\title{
Neutron diffraction analysis on FINEMET alloys
}

\author{
J. Zhu \\ Grup de Física de Materials I, Departament de Física, Universitat Autònoma de Barcelona, \\ 08193 Bellaterra, Spain \\ N. Clavaguera ${ }^{\mathrm{a})}$ \\ Grup de Física de l'Estat Sòlid, Departament ECM, Facultat de Física, Universitat de Barcelona, \\ Diagonal 647, 08028 Barcelona, Spain \\ M. T. Clavaguera-Mora \\ Grup de Física de Materials I, Departament de Física, Universitat Autònoma de Barcelona, \\ 08193 Bellaterra, Spain \\ W. S. Howells \\ ISIS Facility, Rutherford Appleton Laboratory, Chilton, Didcot, Oxon OX11 0QX, United Kingdom
}

(Received 18 May 1998; accepted for publication 12 September 1998)

\begin{abstract}
Neutron diffraction has been used to study in situ the nanocrystallization process of $\mathrm{Fe}_{73.5} \mathrm{Cu}_{1} \mathrm{Nb}_{3} \mathrm{Si}_{22.5-x} \mathrm{~B}_{x}(x=5,9$, and 12) amorphous alloys. Nanocrystallization results in a decrease of both the silicon content and the grain size of the $\mathrm{Fe}(\mathrm{Si})$ phase with increasing value of $x$. By comparing the radial distribution function peak areas with those predicted for ideal bcc and $\mathrm{DO}_{3}$ structure, it can be concluded that the ordering in $\mathrm{DO}_{3} \mathrm{Fe}(\mathrm{Si})$ crystals increases with the silicon content. (C) 1998 American Institute of Physics. [S0021-8979(98)02424-4]
\end{abstract}

\section{INTRODUCTION}

Amorphous $\mathrm{Fe}-\mathrm{Si}-\mathrm{B}$ with small additions of $\mathrm{Cu}$ and $\mathrm{Nb}$, which is commercially available under the trademark FINEMET, possesses excellent magnetic properties after partial crystallization. ${ }^{1-3}$ The microstructure consists of a $\mathrm{Fe}(\mathrm{Si})$ nanocrystalline phase about $10 \mathrm{~nm}$ in size and an amorphous matrix phase. The chemical composition of the $\mathrm{Fe}(\mathrm{Si})$ grains depends on the initial amorphous composition and thermal history, ${ }^{4-6}$ the silicon atoms are not randomly distributed in the $\mathrm{Fe}(\mathrm{Si})$ phase, but mostly occupy the $\mathrm{DO}_{3}$ superlattice sites. ${ }^{7,8}$

Some previous research about the short-range order (SRO) in FINEMET alloys by using x-ray diffraction ${ }^{9}$ compares the interference function and the pair correlation function or radial distribution function (RDF) of initially amorphous samples with several compositions and after annealing at various temperatures, but a detailed discussion about the crystalline phase is still missing.

Neutron diffraction (ND) analysis is a good technique to extend the study of small structural changes not accessible in most other techniques. In this article, the ND is used as an effective tool to measure the influence of the chemical composition on the amorphous and crystallized FINEMET alloys. The SRO changes, especially the relationship between $\mathrm{RDF}$ and the ordered silicon distribution in $\mathrm{Fe}(\mathrm{Si})$ crystalline phase, were investigated.

\section{EXPERIMENT}

Amorphous alloys of nominal composition $\mathrm{Fe}_{73.5} \mathrm{Cu}_{1} \mathrm{Nb}_{3} \mathrm{Si}_{22.5-x} \mathrm{~B}_{x}(x=5,9$, and 12) in the form of rib-

${ }^{\text {a) }}$ Correspondent author; electronic mail: narcis@ecm.ub.es bons of $15 \mathrm{~mm}$ width and about $20 \mu \mathrm{m}$ thickness were studied by ND. The sample ribbons, about $1.5 \mathrm{~m}$ long, were rolled up and inserted into a cylindrical vanadium sample can of $\sim 7 \mathrm{~mm}$ diameter. The spectra of the amorphous samples were taken at $300{ }^{\circ} \mathrm{C}$ for $10 \mathrm{~min}$, and those of the crystallized samples were carried out after annealing at $480{ }^{\circ} \mathrm{C}$ for $14 \mathrm{~h}$.

The ND experiments were carried out at the ISIS Pulsed Neutron Facility at the Rutherford Appleton Laboratory on the liquids and amorphous diffractometer, LAD, by in situ measurements of the diffraction patterns during the heat treatment. ${ }^{10,11}$ The diffraction patterns $S(Q)$ are collected by seven groups of detectors with different scattering angles. The RDF are obtained by Fourier transformation of the $S(Q)$, obtained after the usual corrections, using the program package ATLAS. ${ }^{12}$

\section{RESULTS AND DISCUSSION}

\section{A. SRO of the amorphous samples}

The ND patterns and the RDF for three different amorphous alloys (with $x=5,9$, and 12) are shown in Figs. 1 and 2 , respectively. The experimental RDF are indicated as black square symbols in Fig. 2, with the full lines showing the fitted results. The RDF indicate that the SRO of the amorphous phases are very similar to each other, with a split second peak, which is a form of behavior found for many amorphous metal-metalloid alloys, ${ }^{13}$ and is in agreement with the dense random packing of hard spheres model. If we fit the RDF with Gaussian type peaks, small differences in the RDF can be seen. ${ }^{14}$ The position of the first coordination shell shifts from 2.59 to $2.60 \AA$ and its relative area changes from $22.6 \%$ to $24.0 \%$ when the composition goes from $x$ $=5$ to $x=12$. The second shell splits into two peaks, except 


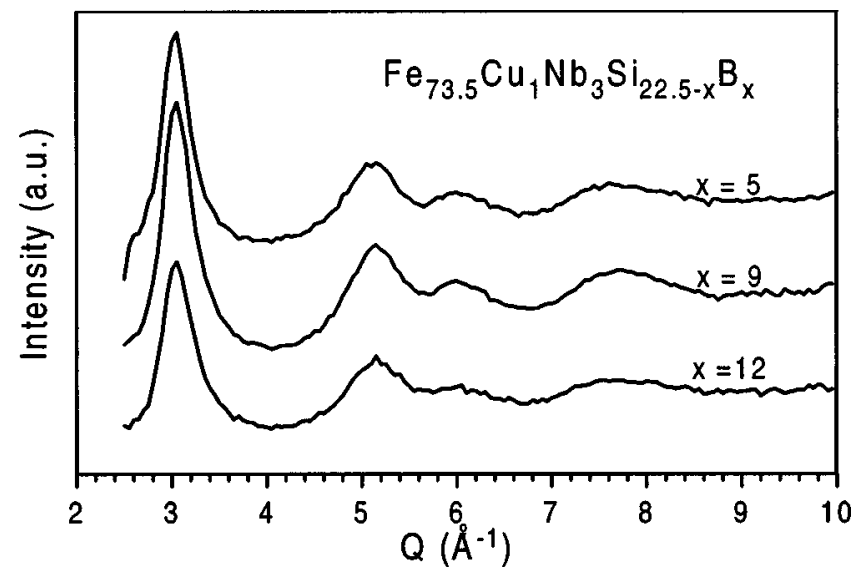

FIG. 1. Neutron diffraction patterns $S(Q)$ of the three amorphous alloys.

for alloy with $x=12$ which can be separated to three peaks, their distances also change from 4.25 to $4.28 \AA$ and from 5.02 to $5.08 \AA$. In the third shell, the differences of the three alloys are clearer. The differences in peak position and relative area on changing nominal composition occur because the different atomic radii of boron and silicon influence the surrounding atomic arrangement. Also, in general, silicon substitutes iron in the network whereas boron modifies the topological SRO.
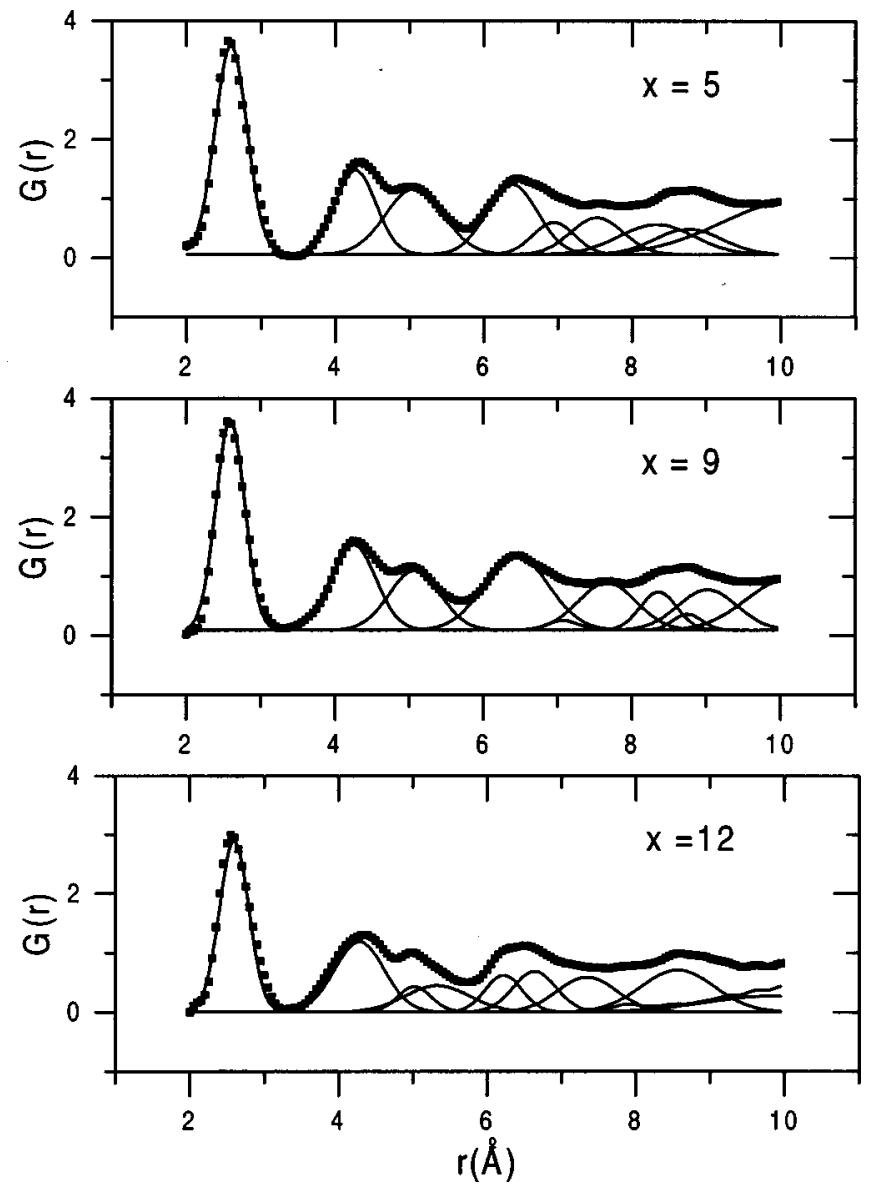

FIG. 2. RDF of three amorphous alloys obtained by Fourier transformation of neutron diffraction patterns $S(Q)$.

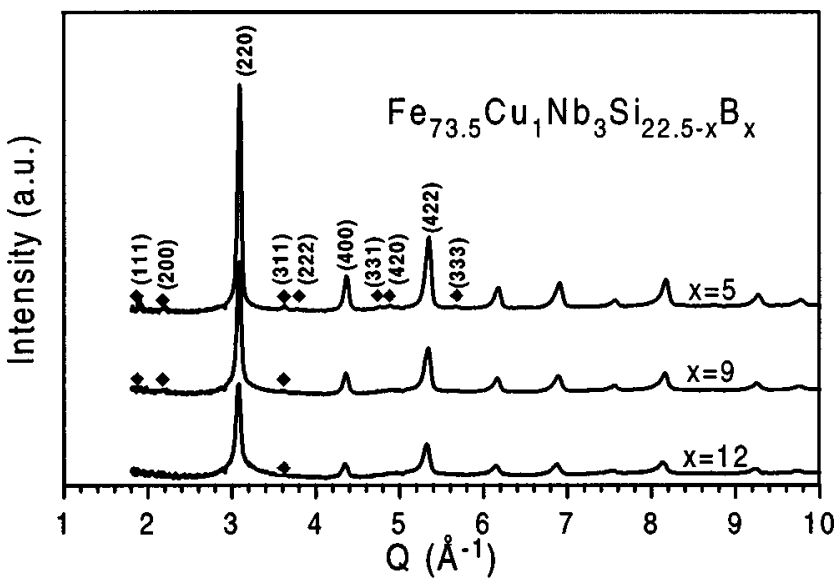

FIG. 3. Neutron diffraction patterns $S(Q)$ of three FINEMET alloys after annealing at $480{ }^{\circ} \mathrm{C}$ for $14 \mathrm{~h}$.

\section{B. LRO of the crystallized state}

The neutron diffraction spectra of amorphous alloys annealed at $480{ }^{\circ} \mathrm{C}$ for $14 \mathrm{~h}$ are shown in Fig. 3. The intensity of the peaks of the crystalline phase increases with the composition of silicon. The remaining amorphous pattern is also seen, as expected, producing broad peaks in the boron rich alloys diffraction patterns. To look for the trends, the fitting of the diffraction pattern was performed assuming the crystalline peaks of Lorentz type and the amorphous of a Gaussian type. The fitting results of $S(Q)$ in the range of 2.5-6 $\AA^{-1}$ for alloy with $x=5$ are shown in Fig. 4. There are some small peaks which belong to the superlattice $\mathrm{DO}_{3}$ ordered structure.

In Fig. 3 the relative intensity of the $\mathrm{DO}_{3}$ peaks indicates that the LRO of the crystalline phase is altered by the change of composition. For alloy with $x=5$ (silicon rich), a $\mathrm{Fe}(\mathrm{Si}$ ) phase close to the ideal $\mathrm{DO}_{3}$ super lattice structure is obtained. In this case, the $\mathrm{DO}_{3}$ peaks appear completely developed. The fitting results shown in Fig. 4 give their position and relative area. But for alloy with $x=12$ (silicon poor) no clear $\mathrm{DO}_{3}$ superlattice peaks appear in the $S(Q)$ pattern. This result agrees with the previous analysis by Mössbauer

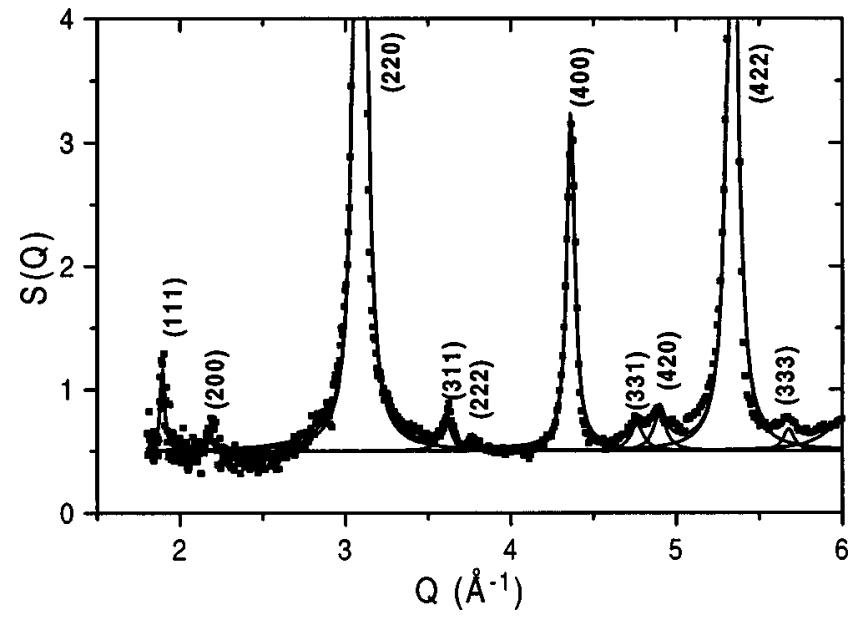

FIG. 4. $S(Q)$ fitted results for the alloy with $x=5$ after annealing at $480{ }^{\circ} \mathrm{C}$ for $14 \mathrm{~h}$. 
TABLE I. Fitted results of $S(Q)$ of alloys annealed at $480{ }^{\circ} \mathrm{C}$ for $14 \mathrm{~h}$ with the diffraction peak position $Q$, the FWHM and relative fraction of crystalline phase. Error estimates: $\pm 0.004 \AA^{-1}(Q)$ and $\pm 0.001 \AA^{-1}$ (FWHM).

\begin{tabular}{cccccccc}
\hline \hline $\begin{array}{c}\text { Alloy } \\
\mathrm{B}(\text { at. \%) }\end{array}$ & $\begin{array}{c}Q_{(222)} \\
\left(\AA^{-1}\right)\end{array}$ & $\begin{array}{c}\mathrm{FWHM}_{(222)} \\
\left(\AA^{-1}\right)\end{array}$ & $\begin{array}{c}Q_{(400)} \\
\left(\AA^{-1}\right)\end{array}$ & $\begin{array}{c}\mathrm{FWHM}_{(400)} \\
\left(\AA^{-1}\right)\end{array}$ & $\begin{array}{c}Q_{(422)} \\
\left(\AA^{-1}\right)\end{array}$ & $\begin{array}{c}\mathrm{FWHM}_{(422)} \\
\left(\AA^{-1}\right)\end{array}$ & $\begin{array}{c}\text { Cryst. Frac. } \\
(\%)\end{array}$ \\
\hline 5 & 3.087 & 0.048 & 4.361 & 0.060 & 5.339 & 0.074 & 97.0 \\
9 & 3.083 & 0.055 & 4.358 & 0.067 & 5.333 & 0.074 & 77.2 \\
12 & 3.075 & 0.063 & 4.344 & 0.074 & 5.321 & 0.080 & 55.7 \\
\hline \hline
\end{tabular}

spectroscopy and X-ray diffraction, which show that the silicon content of the $\mathrm{Fe}(\mathrm{Si})$ phase is related with the initial composition. $^{15-17}$

In Table I are listed the fitted results of $S(Q)$ patterns for the three different alloys. The position of the peaks depends on composition, for instance, the one with Miller index (220), decreases from 3.087 to $3.075 \AA^{-1}$ when the composition changes from $x=5$ to $x=12$. It is due to the silicon content changing in the crystalline $\mathrm{Fe}(\mathrm{Si})$ phase. The full width at half maximum (FWHM) of the peaks is attributed to the mean grain size of the $\mathrm{Fe}(\mathrm{Si})$ crystals. The value of FWHM of peak (220) increases from $0.048(x=5)$ to 0.063 $\AA^{-1}(x=12)$. This effect indicates that the average grain size in the alloy with $x=12$ is smaller than that in the alloy with $x=5$.

Further important information obtained from the fitted results is the relative intensity of the diffraction peaks belonging to crystals and to the remaining amorphous phase. The relative area is related to the transformed fraction. After $14 \mathrm{~h}$ annealing at $480{ }^{\circ} \mathrm{C}$, for the alloy with $x=5$, the transformation is nearly completed (crystalline fraction around $97 \%$ ), for the alloy $x=9$ it is about $77 \%$ and for the alloy with $x=12$ it is only about $56 \%$. The TTT (timetemperature-transformation) diagram for these three FINEMET alloys has been constructed from the calorimetric results by DSC. The TTT diagrams obtained are presented in Fig. 5, it shows that the crystallization of $\mathrm{Fe}(\mathrm{Si})$ in the three alloys occurs at different temperature ranges. In the alloy with $x=5$, the temperature range is lower than for the other two alloys. The annealing temperature selected for neutron diffraction measurement was already over the end line of the transformation for alloy with $x=5$, this is the reason why the crystalline fraction was rather high. For the other two alloys,

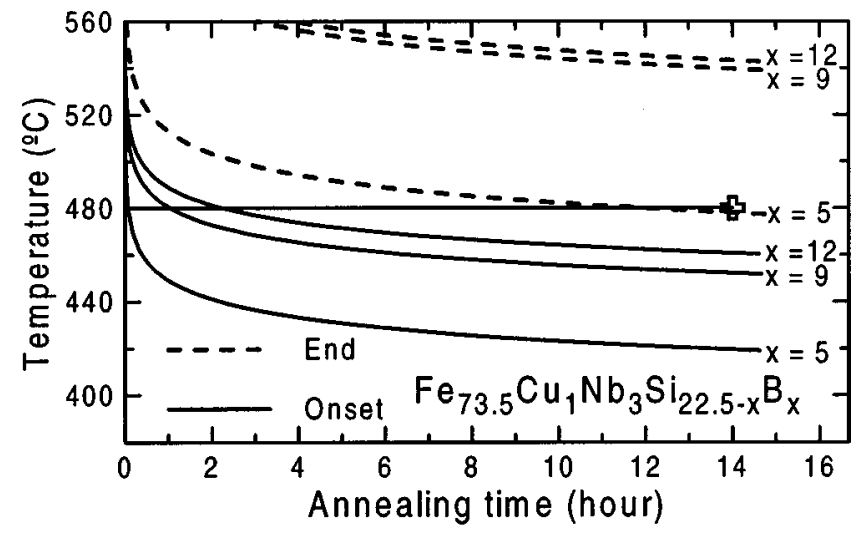

FIG. 5. TTT diagram of crystallization process of three amorphous alloys. the annealing temperature was in between the onset line and the end line. Therefore, the transformed fractions obtained from neutron diffraction pattern are in good agreement with the TTT diagram.

\section{SRO of the crystallized state}

The SRO of the annealed alloys are presented as RDF in Fig. 6 for the three alloys and the calculated RDF for the bcc and $\mathrm{DO}_{3} \mathrm{Fe}(\mathrm{Si})$ phases are shown as a series of delta functions. The SRO are different from the amorphous state shown in Fig. 2. The crystallized fraction effects in the RDF curves are seen in the intensity changes from the amorphous state. The first and third peaks are enhanced as the crystallized fraction increase.

In order to get the RDF of ideal bcc and $\mathrm{DO}_{3}$ structures, we assume them to have the same silicon content and the same lattice parameter. For a binary system, the atomic density can be written as ${ }^{18}$

$$
\rho(r)=\sum_{i, j} w_{i, j} \rho_{i, j}(r),
$$

where $w_{i, j}$ is the effective scattering length of the binary system. $\rho_{i, j}$ is the average number of $j$ atoms in unit volume at a distance $r$ around an atom $i$.

$$
w_{i, j}=\frac{c_{i} f_{i} \cdot f_{j}}{\langle f\rangle^{2}} .
$$

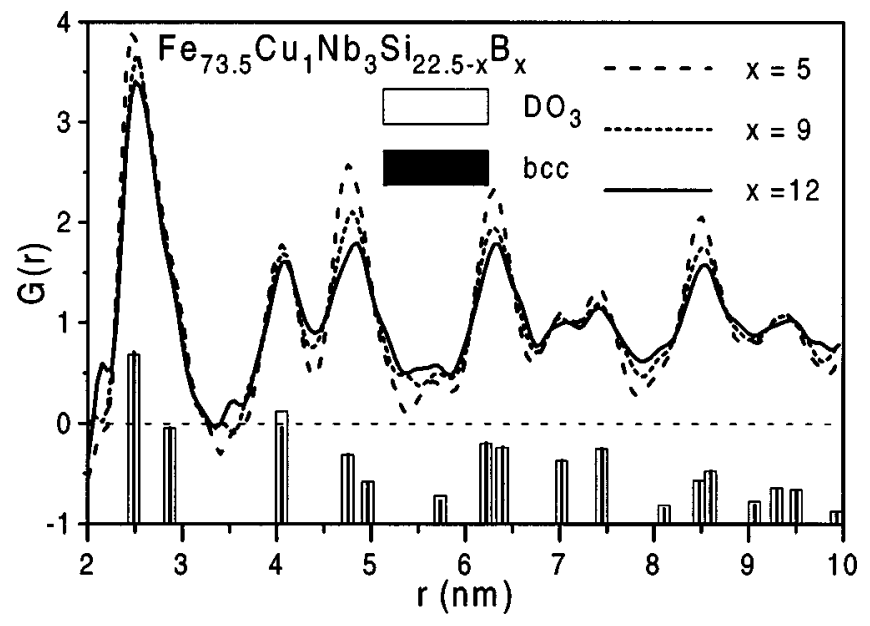

FIG. 6. RDF of three FINEMET alloys after annealing at $480{ }^{\circ} \mathrm{C}$ for $14 \mathrm{~h}$, together with $\mathrm{RDF}$ of bcc and $\mathrm{DO}_{3}$ structure. 
TABLE II. Fitted results of $G(r)$ obtained from Fourier transformation of $S(Q)$ of alloys annealed at $480{ }^{\circ} \mathrm{C}$ for $14 \mathrm{~h}$ with values of first, second, and third near neighbor distance $r_{i}$, the $\mathrm{FWHM}_{i}$ and relative area $A_{i}$. Error estimates: $\pm 0.005 \AA\left(r_{i}\right)$ and $\pm 0.002 \AA\left(\mathrm{FWHM}_{i}\right)$.

\begin{tabular}{ccccccccccc}
\hline \hline $\begin{array}{c}\text { Alloy } \\
\mathrm{B}(\text { at. \% })\end{array}$ & $\begin{array}{c}r_{1} \\
(\AA)\end{array}$ & $\begin{array}{c}\mathrm{FWHM}_{1} \\
(\AA)\end{array}$ & $\begin{array}{c}A_{1} \\
(\%)\end{array}$ & $\begin{array}{c}r_{2} \\
(\AA)\end{array}$ & $\begin{array}{c}\mathrm{FWHM}_{2} \\
(\AA)\end{array}$ & $\begin{array}{c}A_{2} \\
(\%)\end{array}$ & $\begin{array}{c}r_{3} \\
(\AA)\end{array}$ & $\begin{array}{c}\mathrm{FWHM}_{3} \\
(\AA)\end{array}$ & $\begin{array}{c}A_{3} \\
(\%)\end{array}$ & $\begin{array}{c}A_{3} / A_{1} \\
\text { exp. }\end{array}$ \\
\hline 5 & 2.451 & 0.247 & 8.15 & 2.708 & 0.511 & 14.75 & 4.051 & 0.406 & 9.01 & 1.106 \\
9 & 2.482 & 0.293 & 11.83 & 2.762 & 0.428 & 10.70 & 4.054 & 0.417 & 8.73 & 0.738 \\
12 & 2.497 & 0.320 & 14.10 & 2.784 & 0.381 & 8.52 & 4.065 & 0.434 & 8.68 & 0.616 \\
\hline \hline
\end{tabular}

$f_{i}$ is the scattering length of element $i$, normalized to mean scattering length $\langle f\rangle=\Sigma c_{i} f_{i}$. Here $c_{i}$ is the content of element $i$. In our case the scattering length of $\mathrm{Fe}$ and $\mathrm{Si}$ are 0.954 and 0.415 , respectively. The RDF is

$$
G(r)=\frac{N(r)}{N_{0}}
$$

so that we obtain the relation for the apparent coordination number $N(r)$ in terms of the partial coordination number $Z_{i, j}$.

$$
N(r)=\sum_{i, j=1}^{2} \frac{c_{i} f_{i} \cdot f_{j}}{\langle f\rangle^{2}} Z_{i, j}(r),
$$

where $Z_{i, j}(r)$ is the number of $j$ atoms arround $i$ atoms at $r$ distance. In our case, we only consider $\mathrm{Fe}$ and $\mathrm{Si}$ atoms in the crystalline sites of a $\mathrm{Fe}(\mathrm{Si})$ phase. In the bcc structure, all sites in the lattice have the same probability for the occupation by $\mathrm{Fe}$ or $\mathrm{Si}$ atom. For the $\mathrm{DO}_{3}$ structure, only the four sites in the center of the cubic cell with symmetry $\operatorname{Fm} \overline{3} m$ can be occupied by Si atoms. Therefore, for each near neighborhood, the $Z_{i, j}$ are calculated considering the probability of $\mathrm{Fe}$ or $\mathrm{Si}$ occupation in the order of $\mathrm{DO}_{3}$.

As shown in Fig. 6, the interatomic distances and the corresponding number of ideal bcc and $\mathrm{DO}_{3}$ structures of near (in direction of [111]) and next near neighbor (in direction of [100]) have no significant differences, but the third nearest neighbor has different values because at this distance (in [110] direction) the effect of the term in $Z_{\mathrm{Si}, \mathrm{Si}}$ becomes important.

The first peak occurs with a shoulder, due to the existence of two peaks corresponding to the first and second nearest neighbors. We fit the RDF with the peak position as bcc or $\mathrm{DO}_{3}$ structure distribution with a Gaussian shape to take into account the thermal vibrations. The fitted results are shown in Fig. 7 in the range from 2 to $10 \AA$. It seems that all the peaks fitted can be associated with the different near neighbor distances of bcc or $\mathrm{DO}_{3}$ crystalline phase. Even for the alloy with a lot of remaining amorphous phase $(45 \%$ in alloy with $x=12$ ), the crystalline SRO character is rather clearly visible.

The main results of the fitting are listed in Table II. These are the peak distances between first, second, and third near neighbors, their FWHM and relative area. In agreement with the $S(Q)$, the peak distances increase with the composition of $\mathrm{B}$, because of the $\mathrm{Fe}(\mathrm{Si})$ crystalline phase changes; the lattice parameter increases and the silicon content decreases with the increase of B composition.
The FWHM of each peak also changes with composition. It increases for the first and second near neighbor but decreases for the third one. These changes are attributed to both the distribution of interatomic distances and the effects of the remaining amorphous phase. The last effect seems to be more important than the first one in the first and second neighbor peak broadening on increasing $\mathrm{B}$ composition since, as shown in Fig. 5, the amount of amorphous phase after $14 \mathrm{~h}$ at $480{ }^{\circ} \mathrm{C}$ is larger for alloys with $x=9$ and 12 than in alloy with $x=5$.

Most interesting for the present purpose is the consideration of the ratio between the area of the third $\left(A_{3}\right)$ and first $\left(A_{1}\right)$ near neighbor peaks. The calculated value of this ratio for the ideal $\mathrm{DO}_{3}$ structure is $A_{3} / A_{1}=0.668$, higher than the corresponding one (0.562) for the ideal bcc structure. There-
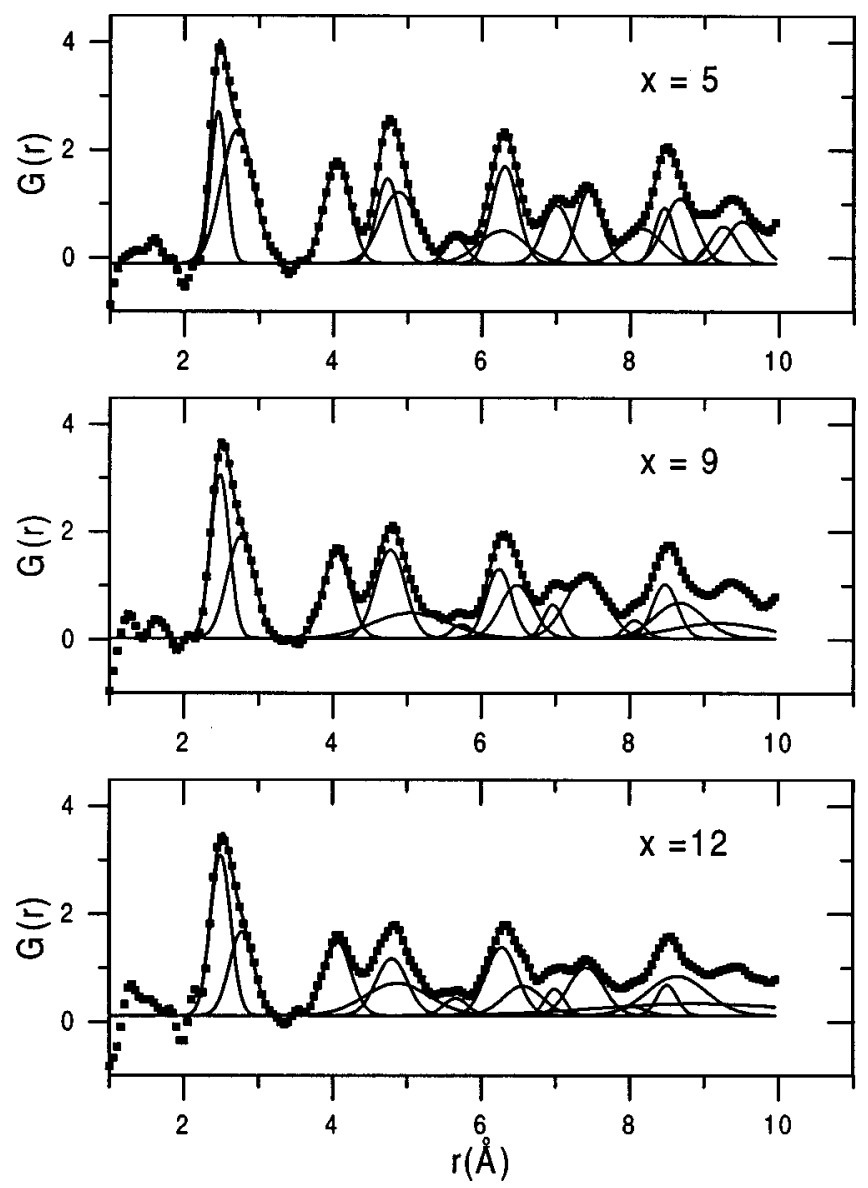

FIG. 7. RDF fitted results of three FINEMET alloys after annealing at $480{ }^{\circ} \mathrm{C}$ for $14 \mathrm{~h}$. 
fore, this value may be considered as a measure of the SRO in the $\mathrm{DO}_{3}$ superlattice. The value of ratio $A_{3} / A_{1}$ obtained for the three alloys, also shown in Table II, indicates that for the alloy with $x=5$, the SRO of the crystalline $\mathrm{Fe}(\mathrm{Si})$ phase is closer to the ideal $\mathrm{DO}_{3}$ one than for the other two alloys.

\section{CONCLUSIONS}

In this article, the SRO in amorphous and crystallized FeCuNbSiB alloys was investigated by neutron diffraction. In the amorphous phase, the radial distribution functions are very similar in all the alloys studied. The small differences encountered are considered to be due to the changes of chemical composition.

The differences between the neutron diffraction patterns of the crystallized alloys result from the changes of both the silicon content and the grain size of the $\mathrm{Fe}(\mathrm{Si})$ phase.

The analysis of the relative area of the diffraction peaks was performed in terms of the degree of crystalline phase achieved after annealing at $480{ }^{\circ} \mathrm{C}$ for $14 \mathrm{~h}$.

The transformed fraction obtained from the analysis agrees with that deduced from the TTT diagrams.

The degree of $\mathrm{DO}_{3}$ ordering in the $\mathrm{Fe}(\mathrm{Si})$ crystals was deduced by comparing the RDF peak areas with those predicted for the ideal bcc and $\mathrm{DO}_{3}$ structures for the same crystalline composition.

The results indicate that the $\mathrm{Fe}(\mathrm{Si})$ crystals obtained after annealing are closer to the ordered $\mathrm{DO}_{3}$ structure for the sample with lower B content in the initial amorphous phase.

\section{ACKNOWLEDGMENTS}

Neutron beam time at the ISIS Facility (RB No. 6925 on LAD), HCM funding of neutron beam at ISIS (J.Z. and
N.C.), and financial support from CICYT (projects MAT960692 and MAT96-0769) are acknowledged. The authors wish also to acknowledge Dr. G. Herzer, Vacuumschmelze $\mathrm{GmbH}$, for providing the amorphous ribbons.

${ }^{1}$ Y. Yoshizawa, S. Oguma and K. Yamauchi, J. Appl. Phys. 64, 6044 (1988).

${ }^{2}$ K. Hono, K. Hiraga, Q. Wang, A. Inoue, and T. Sakurai, Surf. Sci. 266, 285 (1992).

${ }^{3}$ M. Müller, N. Mattern, and L. Illgen, Z. Metallkd. 82, 895 (1991).

${ }^{4}$ A. Hernando and I. Navarro, in Nanophase Materials, edited by G. C. Hadjipanyis and R. W. Siegel (Kluwer, the Netherlands, 1994), p. 703.

${ }^{5}$ A. R. Yavari and O. Drbohlav, Mater. Trans., JIM 36, 896 (1995).

${ }^{6}$ G. Herzer, J. Magn. Magn. Mater. 112, 258 (1992).

${ }^{7}$ M. Müller, N. Mattern, and L. Illgen, J. Magn. Magn. Mater. 112, 263 (1992).

${ }^{8}$ G. Rixecker, P. Schaaf, and U. Gonser, Phys. Status Solidi A 139, 309 (1993).

${ }^{9}$ N. Mattern, M. Müller, C. Stiller, and A. Danzig, Mater. Sci. Eng., A 179/180, 473 (1994).

${ }^{10}$ ISIS Experimental Report 1996 (ISIS96), RB No. 6925, p. A391.

${ }^{11}$ ISIS Experimental Report 1996 (ISIS96), Science at ISIS, p. 16.

${ }^{12}$ A. C. Hannon, W. S. Howells, and A. K. Soper, in Proceedings of the Second Workshop on Neutron Scattering Data Analysis (WONSDA2) 1990, edited by M. W. Johnson, IOP Conf. Ser. Vol. 107 (IOP, Bristol, 1990), p. 193.

${ }^{13}$ G. S. Gargill, Solid State Phys. 30, 91 (1971).

${ }^{14}$ M. Shaal, P. Lamparter, and S. Steeb, Z. Naturforsch., A: Phys. Sci. 43a, 1055 (1988).

${ }^{15}$ T. Pradell, N. Clavaguera, J. Zhu, and M. T. Clavaguera-Mora, J. Phys.: Condens. Matter 7, 4129 (1995).

${ }^{16}$ T. Pradell, N. Clavaguera, J. Zhu, and M. T. Clavaguera-Mora, Conference Proceedings ICAME-95, edited by I. Ortalli (Italian Physical Society, Bologna, 1996), Vol. 50, p. 409.

${ }^{17}$ J. Zhu, T. Pradell, N. Clavaguera, and M. T. Clavaguera-Mora, Mater. Res. Soc. Symp. Proc. 455, 489 (1997).

${ }^{18}$ P. Lamparter and S. Steeb, in Materials Science and Technology, edited by R. W. Cahn, P. Haasen, and E. J. Kramer (VCH, New York, 1993), Vol. 1, pp. 217-288. 